\title{
The Development Value and Utilization Strategy of the Local Culture Education Resources In Hubei Prov
}

\author{
Yanli Wang
}

\begin{abstract}
Hubei Province is one of the birthplaces of Chinese civilization, it has a number of distinctive local characteristics of local culture. The culture does not only show the Chinese language literature in bright light, but also contains a great spirit of the Chinese nation. College course of China plays an important role in mother tongue education, quality education, which undertakes the task of humanistic education, teaching, the establishment of "Chinese language" concept, Hubei local folk culture, regional culture and education resources of local culture by combing the integration after the introduction of the language classroom, the effective development and utilization value of Hubei local education cultural resources in University Chinese teaching. Strategy research and utilization of resources of Chinese native culture develops at the University of education value.
\end{abstract}

Keywords-The local culture ; Educational ; esources; Development; utilization

\section{INTRODUCTION}

The party's eighteen report refers to the Chinese traditional culture, to achieve the great rejuvenation of the Chinese nation. Chinese traditional culture is the root of our national existence, social stability, the foundation of the state. Hubei Province is one of the important birthplaces of Chinese civilization, the distinctive regional culture, such as Jiangcheng culture, Han culture, Chu culture, red culture, Yan Di culture and so on, and other areas of culture together to build a Chinese traditional culture, which is a megastructure. Hubei local culture contains many excellent cultural traditions of the Chinese nation, benevolence, integrity, innovation, patriotism..... It is an important source of cohesion and creativity of the Chinese nation, and it is an important content of building the socialist core value system. College Chinese course bear the responsibility of mother tongue education, undertakes the important task of quality education, humane spirit education, inherit the national culture, foster a sense of students a sense of national pride and sense of national identity, which are the bounden duties of College Chinese course of vocation and mission. College Chinese education of local colleges and universities shall establish the concept of "Chinese language", the Hubei local folk culture and regional culture, local culture and education resources after combing the integration into the language classroom, in College Chinese teaching effectively develop and use of the educational value of the Hubei local cultural resources, in order to make the College
Chinese course is rich in Hubei reg ion culture style, light and blooming of national culture.

\section{LOCAL CULT URE EDUCATION IDEA AND BASIS}

China has a vast territory, and has formed a unique cultural resources in the long-term historical and cultural development. Local culture refers to the culture which is composed of different groups of people. It is a cultural environment that individual or group in the course of development can influence the formation of its perception, thinking, value and so on. The modern education theory holds that the cultural resources are the necessary conditions for the education. In some areas of local culture providing specific historical background and living space for human, often with an invisible force constraints the residents of that region's way of thinking, value orientation, Shifeng folk, "cultural environment as a kind of social existence, is a huge social and cultural effects of field, especially the traditional culture has a strong radiation force and heritability, it often presents as a kind of internal control of historical inertia movement, the role and influence all aspects of social life, caused by various social effect." [1]

Local culture is that people born be have the outstanding cultural achievements of mankind, according to certain standards of value, selection, classification, sorting, and scientifically through the imparting of knowledge, environment influence to internalization into personality, temperament and culture and become a relatively stable inner character of a kind of education process.

"Just because of this, the cultural tradition has become a silent instruction, the power of cohesion, the symbol of the group. Without traditional culture, it is hard to imagine how a nation can exist, how a society can be stable, how a country can be consolidated." [2] in March 2013, President Xi Jinping in the second session of the first meeting of the speech, nine times mentioned "Chinese dream" of the concept, and points out: "to realize the dream of China must take the road of China, must carry forward the spirit of China, must unite the power of China". In March 26, 2014, the Ministry of Education is sued the "perfect Chinese traditional outstanding cultural education guidance," clearly put forward "to further strengthen the new situation of Chinese traditional culture". Central to this series of initiatives to "China" "national" "Chinese traditional culture" and other rich Chinese local color of the cultural concept highlights the. 
The local culture education once again into the social field of vision.

"Language curriculum standard" issued by the Ministry of education clearly pointed out that "the area contains a natural, social, human and other resources of Chinese course, should have a strong sense of resources, to development, actively use." Also stressed that the Chinese teachers should pay great attention to the curriculum resources development and utilization, creatively in all kinds of activities, enhance students on various occasions to learn Chinese, with Chinese consciousness, more improve the language proficiency of students. " [4] as the juris diction of Hubei Province, local colleges and universities, University Chinese course for us, when the guidance in this standard, deeply rooted in the local culture of Hubei, combing a variety of outstanding cultural fusion phenomenon in Hubei regional culture, such as natural landscape, folk art, folk customs and so on, to explore its cultural connotation and educational value, explore the local culture of Hubei outstanding education resources into the good path of the university curriculum, which contains humanistic factors, in the local cultural resources in the development of scientific factors, growth factors, emotional factors can better serve the students, help the University Chinese course to build "integrated learning, all-round development" of the educational ladder. "Teachers should strive to expand the knowledge of the students, so that they are from the fields and woods that know their hometown, and gradually expand to the nature and life of the whole world." [5]

\section{HUBEI LOCAL CULTURE EDUCATION RESOURCES}

\section{DEVELOPMENT VALUE}

\section{A. To cultivate the core values of college students, cultivate their homeland and patriotic consciousness}

Any region of the native culture is in the region's unique geographical environment, formed under the comprehensive effect of multiple factors, politics, economy, customs and habits, condensing the nation and the local unique culture and strong personality, contains the nation's mode of thinking and cognitive style. Therefore, any geographical culture has to cultivate national character, shaping the national spirit, function of inheriting the national culture is heritage of a nation's prosperity foundation, a nation is able to the stability and agglomeration of the spirit of the kernel, is the root of a national cohesion and centripetal force.

From this point of view, implementation of the local culture, to Hubei excellent local cultural resources into education process is not only a long neglected folk cultural resources into the mainstream education, a national memory of ancient life blood continuation process. At the same time, is also a help students to establish the consciousness of "cultural roots: guide the students through the establishment of the local culture of hometown's understanding and recognition, and gradually formed on the identity of the survival and the survival of the national spirit of wisdom, and ultimately to establish a family of town - country for one, love Township and patriotism as one of the national emotion.
In the course of local cultural education, the cultural identity and the establishment of emotion are everywhere. From Hubei Wuxue students in his hometown specialty, Wuxue crunchy candy, just suddenly found that candy the in my life always visible, nondescript snack food, unexpectedly appeared in the Wanli period of the Ming Dynasty, takes its name from the Qing Dynasty emperor. This discovery makes Wuxue Sutang covered with a layer of heavy sense of history, stirring up students buried proud hearts home feeling. From Wudang Mountains of students under the guidance of teachers sort of home culture, know his hometown not only poverty and backwardness, not only has the lonely and occlusion, and a number of the world's non material cultural heritage -- stories from Wujiagou Village, Lvjiahe folk songs, Wudang Taiyi boxing, previously the inferiority and depression swept away, replaced with a sense of honor and the hometown of love feeling.

In process of Chinese teaching in University, consciously into Hubei native culture education, let students recognize that they rely on growing native culture, cultivate local consciousness, establish national emotion, enhance the local cultural identity and ethnic identity identity -- to the motherland of the highly recognized, of the Chinese nation, a high degree of identity, the high degree of recognition of Chinese culture and the socialism with Chinese characteristics is highly recognized. This identity is the spirit of the Chinese nation from generation to generation the continuation of blood, which is conducive to the great nation of the endless reproduction development and revival in cultivating college students' socialist core value concept.

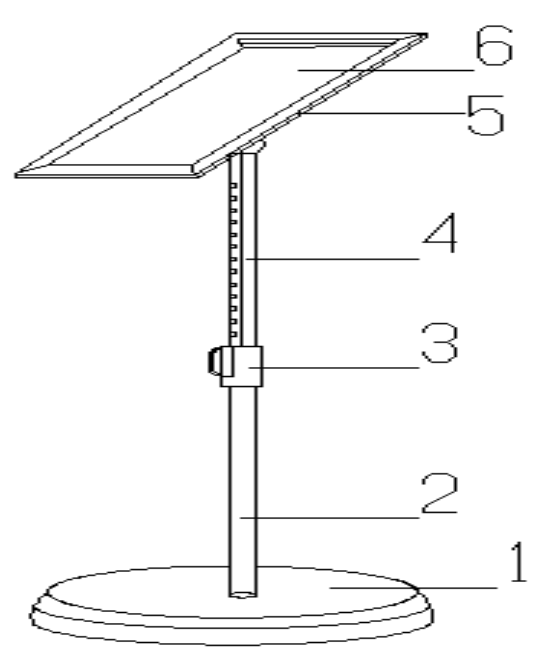

Figure 1.

B. It is helpful to improve the humanistic quality of college students, and to shape the healthy personality of college students.

Indigenous education is one of the greatest features is that it is to occur in the homeland, students understand the hometown of specific culture as the education content. "Each regional culture is a unique geographical 
environment, in the political, economic, cultural and other factors of the comprehensive role of the history of the formation of,...... Life groups in the same region, the basic frame of the cultural and psychological structure of each person, influenced by regional culture exerts a subtle influence, in the cultural psychology of the individual shaped with some geographical and cultural characteristics of the personality, need, motivation, will, emotion and other content. " $[6]$

In the education process, combining the local cultural education and development of students' emotional intelligence, guide the students from the historical and cultural inheritance of "creation and criticis m", inherited from the urban culture in "faith and responsibility", from the celebrity culture inheritance "loyalty and charity", not only can make students are exposed to the hometown of historical stories, folk style and sense of material culture in the familiar "regional atmosphere" and close the "affinity", more deep feelings of the local culture, which contains the values, attitudes, ways of thinking and folk custom culture.

There is a fairy - like character in the martial arts novels, Zhang Sanfeng, he is mainly active in the late period of the Northwest hubei. Speaking of Zhang Sanfeng, from Xiangyang, Shiyan students of this dirty priests have familiar sense of, hundreds of Zhang Sanfeng legends in the with. Teaching of Jin Yong's "swordsman", the students on the character launched a lively discussion. Finally, the paper draws the following conclusions: first, ability is the basic guarantee of a personal fame, Zhang Sanfeng is a spell, martial arts, humor, both the high road; the second, benevolence is the prerequisite for the name of the United States and the achievements of, Zhang Sanfeng Zhou Qiong lifesavers, universal public crossing, love all sentient beings; third, feelings of mind is natural and unrestrained life of gas station, Zhang Sanfeng is teaching a master, but accessible Kuangyuan, indisputable temporalities, regardless of the trivial, sloppy and straightforwardness. Around the discussion of Zhang Sanfeng not only help the teacher to complete the works of the background of the teaching task, more to make the students experience the charm and connotation of local culture, has formed own cultural character and personality, confirm their cultural identity in the monasteries.

In College Chinese teaching, there is a sense of Hubei indigenous culture and education to help college students through their own side of the cultural phenomenon, knowledge of their own culture, feeling and understanding of their own culture, inherit and carry forward the culture of their own, forming their own cultural character and personality, improve the comprehensive quality, shaping perfect personality.

\section{Io improve students' innovative thinking and other cultural ability}

Local culture as a supplement to the mainstream culture and education, common role in the modern education system together to help students form diversified cultural concept, train students and inclusive cultural mentality, train students' criticism and reflection of the cultural value ability and creative thinking ability. First of all, to guide students in the process of understanding of local culture, understanding of regional culture in the presence of cultural value, resulting in cultural sense of belonging, build self-esteem; secondly, guide students to face up to the cultural differences in different regions, the multicultural society of tolerance and respect, trains the student to accept the differences, tolerance of alien culture attitude, promote students' inclusive growth; furthermore, guide students to establish the value orientation of "experience and observe the culvert swims", to crit ical his torical perspective to analyze and acceptance of cultural factors, takes its essence, goes to its dregs, cultivate students' cultural critique ability and the ability to reflect, to cultivate their independent learning ability and creative thinking ability.

The "Xielu Cao Cao" and "song for" two poems are borrowed from the form of writing news Elegy of famous literary works. The so-called elegy is procession singing to the dead said ballad of the sad and miss, is an ancient custom of funeral and interment, this custom today many parts of Hubei is still prevalent. After the teacher simply introduced the text background, students from different places began to actively and enthusiastically exchange their hometown funeral customs. "Xielu" "song" for them is very strange vocabulary, but funeral sing elegy is many students experience the local folk custom, commonly known as "to be dead". Through the exchange, the students found, local funeral customs also really is very different, in some places in three days, in some places unexpectedly reached seven days; in some places only sing the night "corpse song". In some places to singing and three nights. Under the guidance of the teacher, the classmates after school around the topic of their respective to gather to sort out, to thinking, such as the piercing lament "the Hanjiang River to be corpse song culture value I see" "sing, sing, sing, or sing, are where" series of articles, these articles prose, poetry, academic papers, from all levels of express of contemporary college students to the traditional custom of rational thinking, and this process also greatly improve the students' cultural thinking and critical ability.

Local culture is the most familiar educational material for college students, the most likely to inspire them to actively learn and accept the local culture, the establishment of the local culture of the feelings of recognition. This experience is a process of building emotion recognition, and it is also an educational strategy to improve the students' cultural ability and achieve the value goal. In College Chinese teaching, there is a sense of Hubei indigenous culture and education, for instance, the inquisition activities in the discovery and excavation, into the classroom discussion and negotiation, in the teaching process of comparison and questioning can promote students thinking, learning, judgment and choice and cultivate their reflection and criticism, practice and innovation ability in the flesh and blood of the environmental education in middle school.

\section{The close connection between the University's \\ language curriculumand real life}

In the previous view on philosophy of education, course away from the real life of students, resulting in rational knowledge and life world, students passive 
attitude to accept Chinese curriculum imposed on their poetry $\mathrm{Fu}$, resulting in a lot of Chinese classroom teacher impassioned, students sleepy picture, Chinese teacher Tucao said "I moved by the day. Moved to, is touched not you! "Investigate its deep reason, and our Chinese teaching and life is out of line, from the life of the students have a great relationship. Hubei is a province the famous culture, rich and colorful regional cultural content, greatly broaden the College Chinese education, the College Chinese curriculum appeared diversity, specific characteristics and differences of the characteristics, cause of college students of Chinese interest.

The benefit of regional culture on University Chinese culture no longer say. On the tool of the tool, the first of the College Chinese curriculum is the mother tongue education curriculum, and it is the core of the college students to cultivate the ability of listening, speaking, reading, writing and so on. Modern pragmatics is the concept of "context", that is any language is deeply rooted in the local society, the specific language background, do not understand the language of the social culture background, it is impossible to understand the exact meaning of the language. The local culture of Hubei provides a strong background for the College Chinese teaching. Hubei Province under the jurisdiction of the local colleges and universities, teachers and students as the main body of teaching basic from in the region of the same culture, teachers' and students' living habits, ways of thinking are in a same cultural environment gradually influenced, so it has a common cultural background and the same way of thinking. The isomorphism between teachers and students and cultural backgrounds and ways of thinking for mother tongue education provides great convenience, in College Chinese teaching, teachers should make good use of the convenient and appropriate to the local cultural context of language and students' communication and interaction.

\section{THE DEVELOPMENT AND UTILIZATION OF LOCAL}

\section{CULTURE EDUCATION RESOURCES IN HUBEI}

\section{A. The development of the regional culture, enrich the language teaching resources}

From the scenic spots to the character style, from the basic necessities to custom, from poetry to the legendary folk, from the dialects and slang to local opera, Hubei region culture almost covers the aspects of people's lives. The culture, especially the traditional culture of the ancient, or due to age-old impact atrophy, or due to frag mentation of short chapters scattered people, or due to decomposition in earthly matters did not cause people's attention and mixed, good and bad. Development and utilization of these cultural resources can not be blind, random, must after carefully combing and screening, after carding and integration, screening, refining the local culture of Hubei outstanding cultural factors as a source of education into College Chinese teaching.
1) Using the network platform, the establishment of the resource pool, to achieve the sharing of educational resources.

The contemporary society is multimedia + era, network education has been basically covered all aspects of education. Use of the network, the construction of public service platform for the education resources of local culture, to rich text, pictures and video materials formed network resources can not only widen the area of education, and can realize the sharing of resources, reduce the reality education platform of time and space constraints, prompted the local education by means of modern communication technology and across time and space, every school, family, each person deeply! Our school through various efforts, in Wuhan city research project funding support, has built "Wuhan local cultural and educational resources of public services platform" (wuhan.whsky.com). The platform is a regional culture of Wuhan based, to the university language curriculum resources is the core of the local culture resources, its main function is on the regional culture of Wuhan can be integrated into the education of outstanding cultural carding, screening, screening, integration, extraction, and for student information query, browse, download and store the education resources in Internet, interactive learning. The platform is currently being improved in.

2) Launch the students to participate in the collection of information, combing the hometown culture.

Actively guide students to use a variety of channels and methods, such as network, magazine, local Yearbook, field trips, etc., combing the collection of home culture material. Combing cultural collection and teaching of College Chinese teaching, it can not only promote the students' understanding of their hometown culture and emotion, but also get rich Chinese teaching resources. Such as in student initiated "roots and casting the soul" activities, to mobilize the students to collect the outstanding culture of combs in their home, and written. In the activity, pay attention to guiding students - comb and collect only method, but the important is found in thought in the process of sorting and collecting thickness (History) and the depth (Ren Tonggan). To tie in with the event, combine newspaper opened the a "beautiful home" column, devoted to students in the activities of the original excellent article.

\section{B. The use of regional culture, the activation of language classroom teaching,}

Local culture is not only a number of cultural phenomenon, but also a humanistic spirit. It takes the regional based history as the main line, the landscape as the carrier, secular life as the representation, so local culture is in landscape, but not travel; legend, but not literature; language, but not the language. The native cultural resources are developed and used, which cannot only limit it to let students understand some hometown scenery scenic spot, know some customs, praise several snack food, but also must stand in the course of College Chinese mainstream position and have the skills to rub melts in Hubei, geographical and cultural factors, the depth mining the spirit connotation, so as to college Chinese instrumental and humanistic service. 
1) Integrated into the regional culture, expand the text field of vision

College Chinese is a literature text as a carrier for the students to carry out the education of the mother tongue. These chapters in addition to the words, phrases, sentences and mellow exquisite language skills, without exception, deeply describe the author's thoughts and feelings, taste and character. What kind of text education students is not only a test of the big language teachers' eyes, but also a test of the big language teacher's mind and feelings. Hubei has a long history, flourishing style, celebrities come forth in large numbers, for thousands of years wrote numerous poems. 2000 years ago in the Han River to listen to Confucius "Kaleidoscope"; Qu Yuan of the Miluo River side "the people's livelihood and more difficult to"..... Li Bai and Meng Haoran, Su Shi and Mi Fu, Cui Hao, Xu Xiake and many other cultural giants are in the landscape sway over their romantic literary grace. All of this has precious Chinese value, which is the best material for the students to carry on the language education and the humanities education. School textbooks written, should insist on the principle of ability and political integrity simultaneously, appropriate selection of the creation of several local people in Hubei Hubei culture on the excellent article, such as Huanggang Normal University Professor Huang Chong Hao "Huanggang Fu", Wuhan local writer Dong Hongyou "Wuhan wharf culture" and, as an independent unit into teaching materials, widening of College Chinese curriculum in the horizon of the text.

2) Integrated into the regional culture, through the teaching link

College Chinese class is very limited, various factors don't allow us out chunks of time and energy to local culture and education, which requires language teachers should make full use of the space vector of classroom teaching, with thick geographical and cultural knowledge to manage the classroom, emitting a rich village nostalgia "College Chinese classroom, make students enjoy the knowledge of literature in the language classroom, enhance pragmatic competence at the same time, the taste of the true, the good and the beautiful, edify and shaping personality.

The integration of local culture is the teaching of all aspects. Before class, prepare a lesson earnestly from the author's life, the background of the times, try to find point of contact for the text and the local culture, such as the scallion dew line "in the singing of the dirge of customs," Chibi "Su Shi's exile Huangzhou derogatory, and so on. In the analytical text through integration of local cultural factors, such as explaining the "song of Everlasting Sorrow", students are required to choose their own dialect poetry before 8 , and Mandarin comparative evaluation of "raised in purdah did not know" knowledge "the word rhyme problems, guide students to understand the language of the ancient retained phenomenon, understand Putonghua and the dialects of the homogeneous homologous relationship. After class, expand training and provide local culture related to knowledge link, open the students' perspective.

The key is to guide students to explore the cultural characteristics and the value of the text, and to realize the construction of Chinese knowledge.
3) Integrated into the regional culture, the extension of the writing world

To develop students' writing ability, especially the ability of writing, is one of the important tasks in Chinese teaching. The key to the teaching of writing is people-oriented, respect for people's all-round development, so in the teaching, there must be writing skills, writing methods and the students' personality development, habits and professional quality unified, integrated. Many local cultural phenomenon is closely related to students' daily life and cultural phenomenon, is familiar to students, influenced by the cultural phenomenon, it is these cultural phenomena, nourish the students personality, spirit and quality. In writing teaching, combination of these cultural phenomena and writing teaching make life become a student of the biggest writing material, which extends the students' writing world, widens the horizon of students writing. The method cannot only avoid the isolation of students' writing world and real life, make them can really say something, improve their writing ability, but also can arouse the enthusiasm of the students' writing, cultivate their attention to the secular, pay attention to the life of human feelings and cultivate humanistic spirit and professional quality. In writing teaching, try to use different methods to blend in with the regional culture, throughout the guide students from macro angle in writing the writing of Hubei cultural phenomenon, such as the contemporary college students and native culture, survey report, long communication "Wudang heritage and Guardian", training students in a frag mentary descriptions of oral presentation of Hubei Cultural Figurative, such as Hubei character words comment, tongue hometown cuisine, the with me Tour Commentary XXX ".

\section{Relying on the regional culture, to carry out the}

\section{language practice}

College Chinese class is limited, the teaching task is very heavy, the local culture education is not possible to be put in the classroom completely. Therefore, it is a must to make full use of after-school practice activities integrated, the local culture cleverly into Chinese practice activity and single educational activities to the point of view of life of links in depth, the students' learning view from teaching to social extension, to extend the life. For example, in newspapers and Literary Society for the position, open up thematic studies; the forums and lectures, to carry out the local culture of lectures and seminars; and ideological and political course combined, make red cultural visits to the practice; holiday students are required to collect the hometown of scenic spots and historical sites of poems and couplets. All the ways of practice do not only greatly stimulate students' Chinese learning interest, improve the students' language comprehension ability, training the students' language ability in practice, but also greatly impel the Chinese into real life. "Let the Chinese real into life, the language teaching ideas will be more and more perfect, and the Chinese class in the course of the positioning will be more and more clear. "[7]

In summary, the development and utilization of Hubei excellent local traditional culture education resources, carry out and promote local culture education, the position of College Chinese courses, and students together to explore the Hubei Jingchu culture treasure, guide them to 
understand and identify the love of one's hometown of historical culture and cultural landscape, to develop their language skills, enhance their humane quality, cultivate their outlook on life and values, which has a special significance. Way streched endless ahead, the quality education as the leading course of College Chinese, when in the tradition of national culture, carry forward the national spirit, the development of local cultural education continue to explore new methods, open up new ways, carry out the true meaning of implement.

\section{ACKNOWLEDGEMENTS}

In Hubei Province in 2014 on the teaching reform of the subject "dream of China under the background of the Hubei local culture and local colleges and universities humanities education integration practice of' 2014491; Hubei Province in 2015 of Humanities and Social Sciences project "dream of China from the perspective of Wuhan local culture and local colleges and universities humanities education fusion research practice, in Wuhan City Vocational College Ordinance (2015G265); Wuhan City higher education at 2014 research topic" Wuhan City local cultural and educational resources in digital public service system development and construction and utilization of CXY201426 author Wang Yanli / Cell phone \& E-mail13986075075472207066@qq.com Author's address 11-2-501, New Century Baoan Garden, Wuchang District of (Wuhan City), Hubei province Zip code 430064

\section{REFERENCES}

[1] Li Yan. The cultivation of intercultural awareness under the new curriculum standards. Wuhan: Huazhong Normal University, 2004: 55

[2] Guo Xiaoying. Development and utilization of local Chinese curriculum resources [D]. Fujian: Fujian Normal University, 2005: 23

[3] Yang Qifan and other regional characteristics in the cultural quality education of colleges and universities [J]. Journal of Chongqing University of Science and Technology, 2013 (9): $122-125$

[4] $\mathrm{Hu}$ Yunxin. Chinese teaching to the teaching and research of Chinese native cult ure nourish [J]. absorption, 2007 (07): 102-103

[5] Sohomlinsky. Give one hundred suggestions to [M]. teachers in Beijing: Educational Science Publishing House,:99-100 2010

[6] Yang. The local culture in China as a financial study of modern Chinese language teaching [J]. (Teaching Research Edition), 2012 (02): 85-88

[7] Cao Minghai. [M]. Qingdao: Qingdao Ocean High School Press, 2011:363-365

[8] Jia-hui zhang. Cultural resources development and research [D]. Wuhan Huazhong University of Science and t Tchnology. 2012

[9] Ding ling. The Local Culture and Urban Image Research [D]. Central South University. 2007

[10] Shen Ming. University Culture and Local Characteristics [J]. Journal of Education Review. 2009.06

[11] Chen ying. Local University of Wenzhou Local Culture Cognition and Inheritance [J]. Journal of Wenzhou Vocational Technical College. 2013.03

[12] Zheng-gui Chen. Under the Perspective of Regional Culture of College Students' moral Education Analysis [J]. Journal of Guangxi University for Young Cadres. 2013.02. 